\title{
Prognostic Factors of Operated Stage I Non-Small Cell Lung Cancers: A Tertiary Center Long-Term Outcomes
}

\author{
- (- Mustafa Vedat Dogru, ๑ Celal Bugra Sezen, • Volkan Erdogu, @ Cemal Aker, \\ - Abdulsamed Alp, ๑ Semih Erduhan, ๑ Melek Erk, ๑ Aysun Olcmen, ๑ Muzaffer Metin
}

University of Health Sciences Turkey, Yedikule Chest Diseases and Thoracic Surgery Training and Research Hospital, Clinic of Thoracic Surgery, Istanbul, Turkey

\section{Abstract}

\begin{abstract}
Aim: This study aimed to evaluate prognostic factors influencing survival in patients who underwent surgical resection of stage I nonsmall cell lung cancer (NSCLC) in our center.

Methods: A total of 472 patients with stage I NSCLC who were operated between January 2007 and November 2018 were retrospectively analyzed in the study. Patient data was collected using hospital database. The remaining patients were divided into 2 groups: patients younger than 65 years of age (group A) and those aged 65 and over (group B).

Results: The patient group comprised 80 women (16.9\%) and 392 men (83.1\%); 152 patients were aged 65 years or over (32.2\%) and 320 patients were under 65 years of age (81.5\%). The mean follow-up time was 51 months. The 5 -year survival rate was $67.2 \%$ overall. Patients with stage IA1, IA2, IA3, and IB tumors had 5-year survival of 78.1\%, 72.5\%, 77.3\%, and 56.7\%, respectively ( $p=0.009$ ). In multivariate analysis, advanced age ( $\geq 65$ years), large cell carcinoma, left-sided surgery, and higher tumor stage were the most important prognostic factors associated with poorer survival.
\end{abstract}

Conclusion: Advanced age was determined to be an independent poor prognostic factor, and sub-group analyses showed that survival outcome was better with tumors smaller than $1 \mathrm{~cm}$. Based on the results of our study, we believe that the classification of stage I group should be revised in the new edition of lung cancer staging.

Keywords: Survival rate, carcinoma, non-small-cell lung, prognosis

\section{Introduction}

Lung cancer is the most common adult cancer and the leading cause of cancer deaths worldwide and in Turkey. According to the most recent statistics from the Yedikule Chest Diseases and Thoracic Surgery Training and Research Hospital, the age-standardized incidence rate of lung cancer in Turkey was reported as 57.7 in 100000 men and 9.8 in 100000 women (1). Lung cancer patients over 75 years of age are especially challenging in terms of selecting a treatment protocol and approach. While the standard treatment approach recommended for early (stage I) lung cancer is surgical anatomic resection, older patients with advanced disease undergo surgery less frequently than younger patients (2). Despite reports of higher postoperative complication and mortality rates in this population, careful patient selection, preoperative multidisciplinary evaluation, and postoperative rehabilitation provide more moderate survival rates (3-7).

In the eighth edition of the tumor, node, metastasis (TNM) classification, stage I tumors are divided into 4 groups based on survival rates (stage IA $1, \mid \mathrm{A} 2$, IA 3 , and IB) (8). In previous studies, survival rates in the stage I sub group have varied depending on factors such as age, sex, and histological cell type. For early-stage tumors in all age groups, the consensus among many researchers is that survival rates with tumors smaller than $2 \mathrm{~cm}$ are better compared to the other groups (9-12).

Our aim in this study was to determine the impact of advanced age on survival in patients who underwent surgical resection of early non-small cell lung carcinoma

Address for Correspondence: Celal Bugra Sezen, University of Health Sciences Turkey, Yedikule Chest Diseases and Thoracic Surgery Training and Research Hospital, Clinic of Thoracic Surgery, Istanbul, Turkey 
(NSCLC) and evaluate the survival outcomes of stage I tumor subgroups.

\section{Methods}

\section{Study Design}

Data pertaining to patients who underwent surgery due to NSCLC between January 2007 and December 2018 were obtained from a prospective database and analyzed retrospectively. Patients whose data could not be accessed, who underwent sublobar (wedge) resection due to limited respiratory function, functional inoperable patients or were Stage I after neoadjuvant therapy were excluded from the study.

The remaining patients were divided into 2 groups: patients younger than 65 years of age (Group A) and those aged 65 and over (Group B). The ethics committee Yedikule Chest Diseases and Thoracic Surgery Training and Research Hospital and Helsinki approval for the study was obtained from the institutional review board (no: 202054).

\section{Patient Selection}

All patients underwent preoperative thoracic computed tomography (CT) for evaluation of primary disease, as well as positron emission tomography (PET/CT) and cranial magnetic resonance imaging for evaluation of distant metastasis. The pulmonary reserve was assessed by pulmonary function tests. The preoperative mediastinal staging was performed in accordance with the European Society of Thoracic Surgeons (ESTS) guidelines (13).

\section{Postoperative Follow-up}

Patient demographic data, mortality, histopathological characteristics, recurrence, and 5-year survival rates were analyzed. Age, histopathology, tumor Stage, and survival data were obtained from hospital records and the national survival database. Pathologic staging was performed according to the $8^{\text {th }}$ edition of the TNM classification system.

Patients were followed up in collaboration with oncologists by physical examination and thoracic CT every 3 months for the first 2 years, every 6 months from years 2 to 5 , and once a year thereafter. An oncologist was present during all postoperative examinations.

\section{Statistical Analysis}

The patients' demographic and clinical data were evaluated using descriptive statistics. Relationships between categorical data were evaluated using chi-square $\left(\chi^{2}\right)$ or Fisher's Exact test. Student's t and Mann-Whitney $U$ tests were used for comparisons of continuous variables. Survival was evaluated using Kaplan-Meier analysis, and log-rank analysis was performed to compare factors. A $p<0.05$ was considered statistically significant. All tests were performed on SPSS version 22 (IBM Corp., Armonk, NY) statistical software.

\section{Results}

A total of 472 NSCLC patients were included in the study. The patient Group included 80 women (16.9\%) and 392 men (83.1\%). The mean age of the patients was 60.53 $\pm 8.35(r=26-84)$ years. One hundred fifty two patients were aged 65 years or over $(32.2 \%)$ and 320 patients were under 65 years of age $(81.5 \%)$. Left resection was performed in 190 patients (40.3\%), right resection in 282 patients (59.7\%). The histologic type was adenocarcinoma in 247 patients (52.3\%), squamous cell carcinoma in 205 patients (43.4\%), and large-cell carcinoma and adenosquamous cell carcinoma in 20 patients (4.2\%). A mean of $17.57 \pm 9.08$ lymph nodes were removed. The comparison of demographic and histopathological characteristics between the $<65$ and $\geq 65$ age groups is shown in Table 1.

Nine patients (1.9\%) died in the first 90 days. The mean follow-up time was 51 months. The mean survival time was 126 months and the 5 -year survival rate was $67.2 \%$. In the univariate analysis, the 5-year survival rate was $55.2 \%$ for patients over the age of 65 , while this rate was $72 \%$ in patients younger than $65(p<0.001)$. The 5 -year survival rate in right-sided resections was $70.1 \%(p=0.024)$. In terms of histopathology, survival time was significantly longer in squamous cell carcinoma than for other types $(p<0.05)$ (Figure 1). The poorest 5-year survival $(33.2 \%)$ was seen in patients with large-cell and adenosquamous cell carcinomas. Five-year survival rates for patients with Stage IA1, IA2, IA3, and IB tumors were $78.1 \%, 72.5 \%$, $77.3 \%$, and $56.7 \%$, respectively $(p=0.009)$. Patients with tumors $2 \mathrm{~cm}$ or smaller had a 5 -year survival rate of $76.4 \%$ $(p=0.004$ vs. tumors $>2 \mathrm{~cm}$ ) (Figure 2 ).

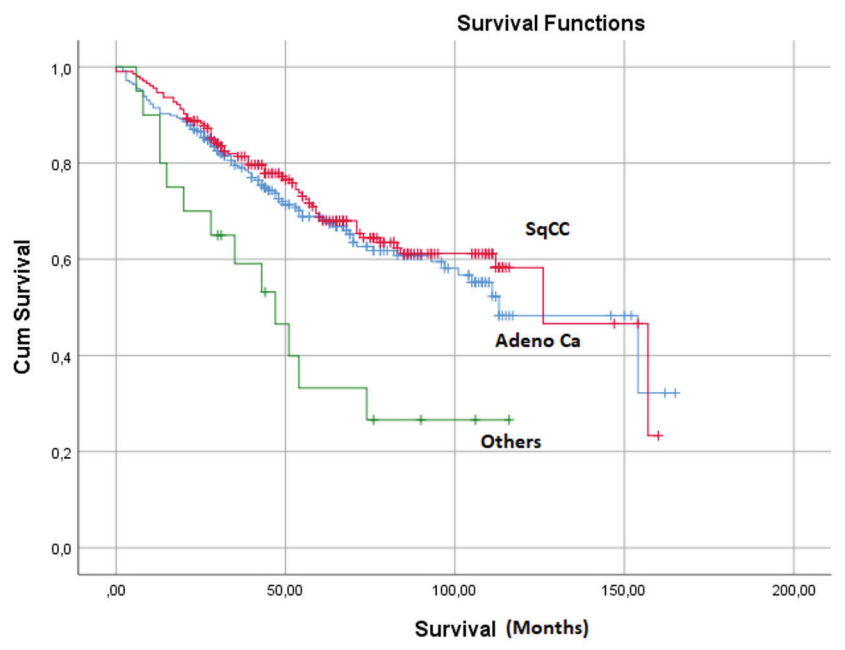

Figure 1. Kaplan-Meier curve of histopathological stage 
In multivariate analysis, age $\geq 65$ years, left-sided resection, large cell and adenosquamous cell cancers, and Stage IB tumors were found to be poor prognostic factors. Table 2 presents the analyses of factors affecting mortality.

\section{Discussion}

Based on the Stage-based survival data obtained in our study, we recommend that Stage I tumors be divided into those $<1 \mathrm{~cm}$ and those between 1 and $4 \mathrm{~cm}$. On

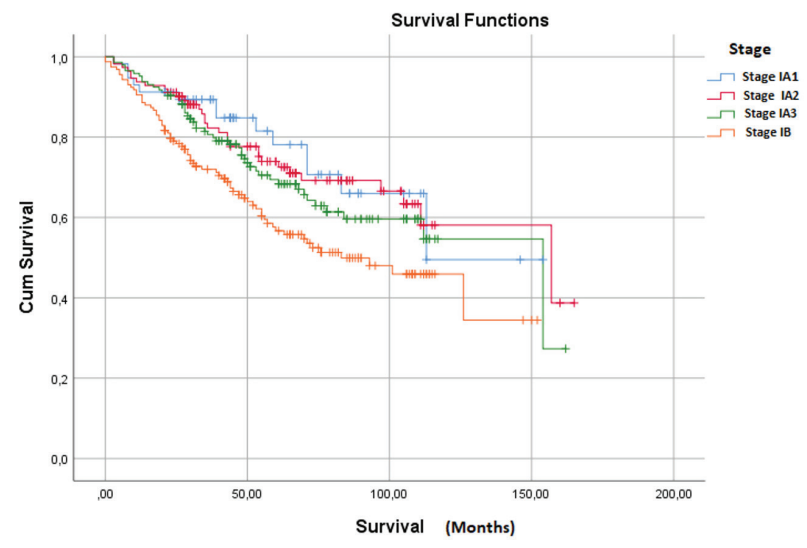

Figure 2. Kaplan-Meier Curve of Stage the $8^{\text {th }}$ edition of the TNM classification for lung cancer, Goldstraw et al. (8) divided Stage I lung cancer tumors into 4 subgroups according to their differences in survival. They determined a statistically significant difference in survival between the groups, with 5-year survival rates of $92 \%$ for Stage IA $1,83 \%$ for IA2, 77\% for IA3, and $68 \%$ in IB tumors (8). Aokage et al. (14) also reported 5-year survival rates in the Stage I subGroup as 95\% in IA $1,84 \%$ in IA2, $76 \%$ in IA3, and $65 \%$ in IB. Stage IA 1 had significantly better survival than the other groups, but there were no significant differences among the Stage IA2, IA 3, and IB groups in terms of survival outcomes. Similar to the study by Aokage et al. (14), multivariate analysis in our study revealed a statistically significant difference in survival between Stage $1 \mathrm{~A} 1$ and $1 \mathrm{~B}$ but no differences between Stage IB and the other groups. Our survival results different from some of publications in the literature, this is due to the performance status of the patients.

Although surgery is considered the gold standard treatment approach in early-stage lung cancer (Stage I-IIA), surgical outcomes in geriatric patients differ compared to those of younger patients. Studies have shown that geriatric patients have poorer survival outcomes compared with younger patients, with this being mainly attributed to

\begin{tabular}{|c|c|c|c|c|c|c|}
\hline \multicolumn{2}{|l|}{ Variable } & \multicolumn{2}{|c|}{$\begin{array}{l}\text { Group A } \\
\text { (<65 years) }\end{array}$} & \multicolumn{2}{|c|}{$\begin{array}{l}\text { Group B } \\
\text { ( } \geq 65 \text { years) }\end{array}$} & \multirow[t]{2}{*}{$p$} \\
\hline & & \multirow{3}{*}{\begin{tabular}{|l|}
$\mathbf{n}$ \\
264 \\
56 \\
\end{tabular}} & \multirow{2}{*}{$\begin{array}{l}\% \\
82.5\end{array}$} & \multirow{2}{*}{\begin{tabular}{|l|}
$\mathbf{n}$ \\
128
\end{tabular}} & \multirow{2}{*}{\begin{tabular}{|l|}
$\%$ \\
84.2
\end{tabular}} & \\
\hline \multirow{2}{*}{ Sex } & Male & & & & & \multirow{2}{*}{0.643} \\
\hline & Female & & 17.5 & 24 & 15.8 & \\
\hline \multicolumn{2}{|c|}{ Age, years (mean $\pm S D)$} & \multicolumn{2}{|c|}{$56.10 \pm 5.77$} & \multicolumn{2}{|c|}{$69.86 \pm 4.26$} & $0.001^{*}$ \\
\hline \multirow{3}{*}{ Resection } & Segmentectomy & 3 & 0.9 & 4 & 2.6 & \multirow{3}{*}{0.111} \\
\hline & Lobectomy & 292 & 91.3 & 142 & 93.4 & \\
\hline & Pneumonectomy & 25 & 7.8 & 6 & 3.6 & \\
\hline \multirow{2}{*}{ Resection side } & Right & 191 & 59.7 & 91 & 59.9 & \multirow{2}{*}{0.970} \\
\hline & Left & 129 & 40.3 & 61 & 40.1 & \\
\hline \multirow{2}{*}{ Operation } & Standard & 298 & 93.1 & 141 & 92.8 & \multirow{2}{*}{0.885} \\
\hline & Sleeve & 22 & 6.9 & 11 & 7.2 & \\
\hline \multirow{3}{*}{ Histopathology } & Adenocarcinoma & 168 & 52.5 & 79 & 52 & \multirow{3}{*}{0.753} \\
\hline & Squamous cell carcinoma & 137 & 42.8 & 68 & 44.7 & \\
\hline & Other & 15 & 4.7 & 5 & 3.3 & \\
\hline \multicolumn{2}{|c|}{ Tumor size, $\mathrm{cm}($ mean $\pm \mathrm{SD})$} & \multicolumn{2}{|c|}{$2.54 \pm 0.99$} & \multicolumn{2}{|c|}{$2.54 \pm 0.91$} & 0.908 \\
\hline \multirow{4}{*}{ Stage } & 1A1 & 40 & 12.5 & 17 & 11.2 & \multirow{4}{*}{0.928} \\
\hline & $1 \mathrm{~A} 2$ & 74 & 23.1 & 38 & 25 & \\
\hline & $1 \mathrm{A3}$ & 97 & 30.3 & 48 & 31.6 & \\
\hline & $1 \mathrm{~B}$ & 109 & 34.1 & 49 & 32.2 & \\
\hline \multicolumn{2}{|c|}{ Lymph nodes removed } & \multicolumn{2}{|c|}{$17.49 \pm 8.65$} & \multicolumn{2}{|c|}{$17.70 \pm 9.95$} & 0.837 \\
\hline
\end{tabular}




\begin{tabular}{|c|c|c|c|c|c|c|c|}
\hline \multirow{2}{*}{\multicolumn{2}{|c|}{ Variables }} & \multirow{4}{*}{$\begin{array}{l}\text { 5-year survival } \\
\text { (\%) }\end{array}$} & \multirow{4}{*}{\begin{tabular}{|l}
$\begin{array}{l}\text { Median } \\
\text { survival } \\
\text { (months) }\end{array}$ \\
154 \\
98 \\
\end{tabular}} & \multirow{4}{*}{$\begin{array}{l}95 \% \mathrm{Cl} \\
100-207 \\
40-101\end{array}$} & \multirow{4}{*}{\begin{tabular}{|l|} 
Univariate \\
$\mathbf{p}$ \\
0.001
\end{tabular}} & \multicolumn{2}{|l|}{ Multivariate } \\
\hline & & & & & & HR $(95 \% \mathrm{Cl})$ & $p$ \\
\hline \multirow{2}{*}{ Age, years } & $<65$ & & & & & $102(130265)$ & L 0001 * \\
\hline & $\geq 65$ & & & & & $1.92(1.38-2.65)$ & $<0.001^{n}$ \\
\hline \multirow{2}{*}{ Sex } & Male & 66 & 103 & $89-136$ & \multirow{2}{*}{0.157} & \multirow{2}{*}{-} & \\
\hline & Female & 71 & 90 & $80-100$ & & & \\
\hline \multirow{2}{*}{ Side } & Right & 70.1 & 154 & $100-207$ & \multirow{2}{*}{0.024} & \multirow{2}{*}{$1.37(1-1.8)$} & \multirow{2}{*}{$0.047^{*}$} \\
\hline & Left & 62.8 & 97 & 69-124 & & & \\
\hline \multirow{2}{*}{ Resection } & Lobectomy & 67.3 & 126 & $95-156$ & \multirow{2}{*}{0.334} & \multirow{2}{*}{-} & \\
\hline & Pneumonectomy & 61.5 & 84 & $64-103$ & & & \\
\hline \multirow{3}{*}{ Histopathology } & Adenocarcinoma & 68.9 & 113 & $87-138$ & \multirow{3}{*}{0.004} & - & 0.001 \\
\hline & $\mathrm{SqCC}$ & 81.4 & 126 & 97-154 & & $0.77(0.5-1.0)$ & 0.125 \\
\hline & Other & 33.2 & 47 & $27-66$ & & $2.58(1.4-4.6)$ & $0.002^{*}$ \\
\hline \multirow{4}{*}{$\begin{array}{l}\text { TNM Stage } \\
\left(8^{\text {th }} \text { ed }\right)\end{array}$} & 1A1 & 78.1 & 113 & $91-129$ & \multirow{4}{*}{0.009} & $0.57(0.39-0.38)$ & $0.004^{*}$ \\
\hline & $1 \mathrm{~A} 2$ & 72.5 & 157 & $79-234$ & & $2288(0-2.96)$ & 0.836 \\
\hline & $1 \mathrm{~A} 3$ & 77.3 & 154 & $70-237$ & & $2022(0-2.62)$ & 0.840 \\
\hline & $1 \mathrm{~B}$ & 56.7 & 83 & $56-109$ & & - & 0.036 \\
\hline \multirow{2}{*}{ Tumor size } & $<2 \mathrm{~cm}$ & 76.4 & 157 & $99-214$ & \multirow{2}{*}{0.004} & \multirow{2}{*}{$481(0-6.23)$} & \multirow{2}{*}{0.822} \\
\hline & $>2 \mathrm{~cm}$ & 62 & 112 & $84-139$ & & & \\
\hline \multirow{2}{*}{ Resection type } & Standard & 67.1 & 154 & $95-212$ & \multirow{2}{*}{0.992} & \multirow{2}{*}{-} & \\
\hline & Sleeve & 69.3 & 126 & $47-204$ & & & \\
\hline
\end{tabular}

age-related tissue fragility, physiological changes (reduced performance and respiratory capacity), and surgical risks $(11,15-20)$. Park et al. (3) observed a major difference in survival between geriatric and young patients (5-year survival of $69 \%$ vs. $91 \%$, respectively). Differences in 5 -year survival between older and younger patients were also reported by Goodgame et al. (21) (52\% vs. 67\%) and Sigel et al. (22) (63.5\% vs. 69.2\%). Consistent with the literature, postoperative 5-year survival was poorer among geriatric patients in our study when compared with the younger patient Group (55.2\% vs. $72 \%$ ).

In contrast to other studies in the literature, Cerfolio and Bryant (23) found that 5-year survival was better in their geriatric patient Group than the young patient Group (78\% vs. 69\%). The differences among these studies may be related to the retrospective design of most studies, differences in the selection of patients for surgical resection, and variation between surgical protocols [sublobar resection (wedge resection, segmentectomy), lobar resection] among clinics. In addition, older age has been associated with poorer survival outcomes even within the geriatric population. In a study conducted in the US, patients over 80 years of age had a 5 -year survival rate below $40 \%$ (24).
Stereotactic body radiotherapy (SBRT) has been increasingly used in the treatment of geriatric patients with early-stage NSCLC in recent years. However, although SBRT significantly improved survival outcomes in patients who were considered inoperable and those who refused surgical treatment or in clinics that revised the treatment protocol for this patient group, the success rate is still much lower when compared with surgery $(16,25)$. Ruiter et al. (16) compared patients who underwent surgery and those who had SBRT and reported a 5-year overall survival of $62 \%$ in the surgery group and $29 \%$ in the SBRT group. Successful outcomes have been achieved with SBRT in primary local control of the disease. For example, in the radiation therapy oncology Group 0236 trial, the 3-year primary disease control rate was reported to be $97.6 \%$, and the 3-year survival rate was $55.8 \%$ (26). Despite the lower toxicity and better early-stage mortality and survival outcomes reported with SBRT, it has not been able to replace surgery in terms of long-term survival. Of course, the overall performance status, inoperability criteria, and respiratory capacity of patients who underwent SBRT should not be overlooked. When patients who undergo surgery are evaluated in terms of these criteria, they have considerable advantages. In our clinic, we operate on all 
patients who have performance capacity amenable to surgery. We expect the ongoing randomized prospective studies on this subject (VALOR, POSTILV) to yield more objective results.

Evaluation of the effect of surgical resection type on survival has produced different results. When the survival rates of lobectomy and pneumonectomy patients in our study were compared, the lobectomy Group had a higher survival rate but the difference was not statistically significant $(p=0.334)$. Similarly, in our previous series we observed no difference in survival between geriatric patients who underwent lobectomy, segmentectomy, and pneumonectomy groups. Additionally, no significant differences in long-term survival and recurrence rates were reported in studies comparing sublobar and lobar resections in early-stage geriatric populations (4). In one such study conducted by Fiorelli et al. (27), the 5-year survival rate among 239 patients was $60.5 \%$ in the lobar resection Group and $45 \%$ in sublobar resection group, but the difference was found not to be statistically significant $(p=0.1)$. Dell'Amore (28) also reported no difference in survival between lobectomy and sublobar resection patients $(p=0.6)$. However, some authors argue that pneumonectomy adversely affects mortality and longterm survival outcomes compared to other resection types (29-31). In the study by Goodgame et al. (21), the pneumonectomy Group had the highest rate of perioperative mortality. In addition, the pneumonectomy Group exhibited significant differences in terms of recurrence and overall survival $(p=0.0003, p=0.043$, respectively). It was argued that survival rates were low because pneumonectomy increases perioperative mortality and considerably increases the rate of postoperative complications in geriatric patients. We believe that the discrepant results of these studies can be attributed to factors such as surgical technique and surgeon experience, differences in preoperative evaluation, heterogeneous patient groups, postoperative rehabilitation, the method of selecting suitable candidates for the resection types, and neoadjuvant/adjuvant treatment protocols.

Most survival studies in the early-stage NSCLC geriatric patient population have reported better histopathological outcomes in the adenocarcinoma Group $(11,32,33)$. In their study of 1116 patients, Ganti et al. (34) detected a significant difference in survival in the adenocarcinoma group. A multivariate analysis conducted by Bei et al. (11) showed adenocarcinoma to be an independent factor of better prognosis in early-stage octogenarians. Hino et al. (35) included all Stage groups in their evaluation and determined that patients with adenocarcinoma had a significantly higher survival rate than the other groups $(p=0.016)$. In other studies, similar survival outcomes were reported in all histopathology groups (adenocarcinoma, squamous cell carcinoma, large-cell) [Dell'Amore et al. (28), 2014; Razi et al. (36), 2016]. In contrast to these studies, multivariate analysis in our study indicated that the large-cell and adenosquamous cell Group had the poorest prognosis in terms of overall survival. There was no statistically significant difference between adenocarcinoma and squamous cell carcinoma.

\section{Study Limitations}

Potential sources of bias in this study include the retrospective study design and the smaller proportion of women in the study sample. Furthermore, the operations included in the analysis were performed by different surgeons, and the patients' performance status was not evaluated. Another shortcoming of this study is that disease-free survival was not calculated for these patients.

\section{Conclusion}

Advanced age is an important prognostic factor in stage I lung cancer. Early-stage large-cell and adenosquamous cancer have the worst prognosis. There was no difference in survival between adenocarcinoma and squamous cell carcinoma in this study. Based on our results, we believe that revision of the Stage I classification is warranted in the next edition of the TNM staging. However, more comprehensive multi-center studies on this subject are still needed.

\section{Authorship Contributions}

Concept: M.V.D., C.B.S., A.A., S.E., M.E., A.O., M.M., Design: M.V.D., C.B.S., V.E., C.A., Data Collection or Processing: M.V.D., C.B.S., V.E., C.A., A.A., S.E., M.E., A.O., M.M., Analysis or Interpretation: M.V.D., C.B.S., Literature Search: M.V.D., C.B.S., A.O., M.M., Writing: M.V.D., C.B.S., A.O., M.M.,

Conflict of Interest: No conflict of interest was declared by the authors.

Financial Disclosure: The authors declared that this study received no financial support.

\section{References}

1. KARA F. Türkiye kanser istatistikleri 2016. Türkiye Cumhuriyeti Sağlık Bakanlığı Halk Sağlığı Genel Müdürlüğü. 2019. Available from: https://hsgm.saglik.gov.tr/tr/kanser-istatistikleri/ yillar/2016-yili-turkiye-kanser-i-statistikleri.html

2. Wouters MW, Siesling S, Jansen-Landheer ML, et al. Variation in treatment and outcome in patients with non-small cell lung cancer by region, hospital type and volume in the Netherlands. Eur J Surg Oncol 2010;36:83-92.

3. Park B, Lee $\mathrm{G}$, Kim HK, et al. A retrospective comparative analysis of elderly and younger patients undergoing pulmonary resection for Stage I non-small cell lung cancer. World J Surg Oncol 2016;14:13. 
4. Sezen CB, Gokce A, Kalafat CE, Aker C, Tastepe Al. Risk factors for postoperative complications and long-term survival in elderly lung cancer patients: a single institutional experience in Turkey. Gen Thorac Cardiovasc Surg 2019;67:442-9.

5. Okami J, Higashiyama M, Asamura $H$, et al. Pulmonary resection in patients aged 80 years or over with clinical Stage I non-small cell lung cancer: prognostic factors for overall survival and risk factors for postoperative complications. J Thorac Oncol 2009;4:1247-53.

6. Sezen Al, Sezen CB, Yildirim SS, et al. Cost analysis and evaluation of risk factors for postoperative pneumonia after thoracic and cardiovascular surgery: a single-center study. Curr Thorac Surg 2019;4:56-62.

7. Sezen CB, Akboga SA, Tastepe Ai, Dem ircan S. Long-Term Outcomes of Chest Wall Resection in Non-Small Cell Lung Cancer in Geriatric Patients. Med Bull Haseki 2018;56:28691.

8. Goldstraw P, Chansky K, Crowley J, et al. The IASLC Lung Cancer Staging Project: Proposals for Revision of the TNM Stage Groupings in the Forthcoming (Eighth) Edition of the TNM Classification for Lung Cancer. J Thorac Oncol 2016;11:39-51.

9. Rami-Porta R, Asamura H, Travis WD, Rusch VW. Lung cancer - major changes in the American Joint Committee on Cancer eighth edition cancer staging manual. CA Cancer J Clin 2017;67:138-55.

10. Zeng Y, Mayne N, Yang CJ, et al. A Nomogram for Predicting Cancer-Specific Survival of TNM 8th Edition Stage I Non-smallcell Lung Cancer. Ann Surg Oncol 2019;26:2053-62.

11. Bei $Y$, Chen $X$, Raturi VP, et al. Treatment patterns and outcomes change in early-stage non-small cell lung cancer in octogenarians and older: a SEER database analysis. Aging Clin Exp Res 2021;33:147-56.

12. Sezen $C B$, Kilimci $U$, Girgin $O$, et al. Is surgical treatment effective option for survival of small cell lung cancer? Curr Thorac Surg 2018;3:110-5.

13. Rusch VW, Asamura H, Watanabe H, Giroux DJ, Rami-Porta R, Goldstraw P; Members of IASLC Staging Committee. The IASLC lung cancer staging project: a proposal for a new international lymph node map in the forthcoming seventh edition of the TNM classification for lung cancer. J Thorac Oncol 2009;4:568-77.

14. Aokage K, Miyoshi T, Ishii G, et al. Influence of Ground Glass Opacity and the Corresponding Pathological Findings on Survival in Patients with Clinical Stage I Non-Small Cell Lung Cancer. J Thorac Oncol 2018;13:533-42.

15. Jin X, Zhao X, Liu X, Han K, Lu G, Zhang Y. Non-Small Cell Lung Cancer in Young Patients: An Analysis of Clinical, Pathologic and TNM Stage Characteristics Compared to the Elderly. Risk Manag Healthc Policy 2020;13:1301-7.

16. de Ruiter JC, Heineman DJ, Daniels JM, van Diessen JN, Damhuis RA, Hartemink KJ. The role of surgery for Stage
I non-small cell lung cancer in octogenarians in the era of stereotactic body radiotherapy in the Netherlands. Lung Cancer 2020;144:64-70.

17. Onaitis MW, Furnary AP, Kosinski AS, et al. Prediction of LongTerm Survival After Lung Cancer Surgery for Elderly Patients in The Society of Thoracic Surgeons General Thoracic Surgery Database. Ann Thorac Surg 2018;105:309-16.

18. Pawlak K, Gabryel P, Kujawska A, et al. Long-term results of surgical treatment of non-small cell lung cancer in patients over 75 years of age. Kardiochir Torakochirurgia Pol 2018; 15:65-71.

19. Shoji F, Matsubara T, Kozuma Y, et al. Preoperative Geriatric Nutritional Risk Index: A predictive and prognostic factor in patients with pathological Stage I non-small cell lung cancer. Surg Oncol 2017;26:483-8.

20. Dogru MV, Sezen CB, Aker C, et al. Evaluation of factors affecting morbidity and mortality in pneumonectomy patients. Acta Chir Belg 2020:1-7.

21. Goodgame B, Viswanathan A, Zoole J, et al. Risk of recurrence of resected Stage I non-small cell lung cancer in elderly patients as compared with younger patients. J Thorac Oncol 2009;4:1370-4.

22. Sigel K, Bonomi M, Packer S, Wisnivesky J. Effect of age on survival of clinical Stage I non-small-cell lung cancer. Ann Surg Oncol 2009;16:1912-7.

23. Cerfolio RJ, Bryant AS. Survival and outcomes of pulmonary resection for non-small cell lung cancer in the elderly: a nested case-control study. Ann Thorac Surg 2006;82:424-9.

24. Trifiletti DM, Hill C, Sharma S, Simone II CB, Showalter TN, Grover S. Early-stage non-small cell lung cancer in the USA: patterns of care and survival among elderly patients at least 80 years old. J Radiat Oncol 2017;6:255-63.

25. Bei Y, Murakami N, Nakayama Y, et al. Stereotactic body radiation therapy for early-stage non-small-cell lung cancer in octogenarians and older: an alternative treatment. J Radiat Res 2020;61:586-93.

26. Khorfan R, Kruser TJ, Coughlin JM, Bharat A, Bilimoria KY, Odell DD. Survival of Primary Stereotactic Body Radiation Therapy Compared With Surgery for Operable Stage I/II Nonsmall Cell Lung Cancer. Ann Thorac Surg 2020;110:228-34.

27. Fiorelli A, Caronia FP, Daddi N, et al. Sublobar resection versus lobectomy for Stage I non-small cell lung cancer: an appropriate choice in elderly patients? Surg Today 2016;46:1370-82.

28. Dell'Amore A, Monteverde M, Martucci N, et al. Lobar and sub-lobar lung resection in octogenarians with early Stage non-small cell lung cancer: factors affecting surgical outcomes and long-term results. Gen Thorac Cardiovasc Surg 2015;63:222-30.

29. Tantraworasin A, Siwachat S, Tanatip N, et al. Outcomes of pulmonary resection in non-small cell lung cancer patients older than 70 years old. Asian J Surg 2020;43:154-65. 
30. Mizushima Y, Noto H, Sugiyama S, et al. Survival and prognosis after pneumonectomy for lung cancer in the elderly. Ann Thorac Surg 1997;64:193-8.

31. Leo F, Scanagatta P, Vannucci F, Brambilla D, Radice D, Spaggiari L. Impaired quality of life after pneumonectomy: who is at risk? J Thorac Cardiovasc Surg 2010;139:49-52.

32. Nakao M, Ichinose J, Matsuura Y, Okumura S, Mun M. Outcomes after thoracoscopic surgery in octogenarian patients with clinical NO non-small-cell lung cancer. Jpn J Clin Oncol 2020;50:926-932.

33. Wang BY, Huang JY, Chen HC, et al. The comparison between adenocarcinoma and squamous cell carcinoma in lung cancer patients. J Cancer Res Clin Oncol 2020;146:43-52.
34. Ganti AK, Shostrom V, Alorabi M, et al. Early Stage Non-SmallCell Lung Cancer in Octogenarian and Older Patients: A SEER Database Analysis. Clin Lung Cancer 2016;17:285-91.

35. Hino H, Murakawa T, Ichinose J, et al. Results of Lung Cancer Surgery for Octogenarians. Ann Thorac Cardiovasc Surg 2015;21:209-16.

36. Razi SS, John MM, Sainathan S, Stavropoulos C. Sublobar resection is equivalent to lobectomy for T1a non-small cell lung cancer in the elderly: a Surveillance, Epidemiology, and End Results database analysis. J Surg Res 2016;200:683-9. 